\title{
Nitric Oxide via cGMP-Dependent Mechanisms Increases Dye Coupling and Excitability of Rat Supraoptic Nucleus Neurons
}

\author{
Qin Z. Yang and Glenn I. Hatton \\ Department of Neuroscience, University of California, Riverside, California 92521
}

\begin{abstract}
Unlike many neuron populations, supraoptic nucleus (SON) neurons are rich in both nitric oxide synthase (NOS) and the NO receptor-soluble guanylyl cyclase (GC), the activation of which leads to cGMP accumulation. Elevations in cGMP result in increased coupling among SON neurons. We investigated the effect of $\mathrm{NO}$ on dye coupling in SONs from male, proestrus virgin female, and lactating rats. In 167 slices 263 SON neurons were recorded; 210 of these neurons were injected intracellularly (one neuron per SON) with Lucifer yellow (LY). The typically minimal coupling seen in virgin females was increased nearly fourfold by the NO precursor, L-arginine, or the NO donor, sodium nitroprusside (SNP). L-Arginine-induced coupling was abolished by a NOS inhibitor. In slices from male and lactating rats who have a higher basal incidence of coupling, SNP increased coupling by approximately twofold over control $(p<$ 0.03). SNP effects were prevented by the NO scavenger hemo-
\end{abstract}

Studies of the distribution of neuronal nitric oxide synthase (NOS) have shown this enzyme to be abundant in the dendrites, somata, and axon terminals of the neurons constituting the magnocellular hypothalamo-neurohypophysial system (Bredt et al., 1990; Dawson et al., 1991). Neurons of this system synthesize, transport, and release either oxytocin or vasopressin, and NOS has been found to be colocalized with both of these peptides (Sanchez et al., 1994). NO is a membrane-permeant neuronal messenger that is produced from L-arginine by the activation of NOS. Typically, NO release from one cell type finds its way to its receptor, soluble guanylyl cyclase (sGC), in nearby (within 200 $\mu \mathrm{M})$ target cells of another type, activating this enzyme and elevating intracellular cGMP levels (Southam and Garthwaite, 1993; Wood and Garthwaite, 1994). Magnocellular neurons of the paraventricular and supraoptic (SON) nuclei are atypical in that they are rich not only in NOS but also in both the $\alpha 1$ and $\beta 1$ subunits of sGC (Furuyama et al., 1993). Because this situation allows for $\mathrm{NO}$ activation of sGC within the same neuron as well as between any nearby magnocellular neurons, it is possible that NO plays an autoregulatory role in at least some of the cGMPdependent processes in these neurons.

Recently, it has been shown that the incidence of interneuronal dye coupling (the number of coupled cells) and the extent of the coupled network (the numbers of neurons coupled to each neu-

\footnotetext{
Received Sept. 17, 1998; revised March 15, 1999; accepted March 18, 1999.

This research was supported by National Institutes of Health Research Grants R01 NS09140 and R01 NS16942 from National Institute of Neurological Disorders and Stroke. We thank Dr. Z.-H. Li for helpful comments on an earlier draft of this paper and J. Kitasako for technical assistance.

Correspondence should be addressed to Dr. Glenn I. Hatton, Department of Neuroscience, University of California, Riverside, CA 92521.

Copyright (C) 1999 Society for Neuroscience 0270-6474/99/194270-10\$05.00/0
}

globin $(20 \mu \mathrm{M})$ and by the selective blocker of NO-activated GC, ODQ $(10 \mu \mathrm{M})$. These results suggest that NO released from cells within the SON can expand the coupled network of neurons and that this action occurs via cGMP-dependent processes. Because increased coupling is associated with elevated SON neuronal excitability, we also studied the effects of 8-bromocGMP on excitability. In both phasically and continuously firing neurons 8-bromo-cGMP (1-2 mM), but not cGMP, produced membrane depolarizations accompanied by membrane conductance increases. Conductance increases remained when depolarizations were eliminated by current-clamping the membrane potential. Thus, NO-induced cGMP increases SON neuronal coupling and excitability.

Key words: gap junctions; guanylyl cyclase inhibition; hemoglobin; L-NAME; ODQ; sodium nitroprusside; 8-bromo-cGMP

ron) in the SON were increased either via receptor-mediated activation of GC or by directly elevating intracellular cGMP levels (Hatton and Yang, 1996). Conversely, elevating cAMP levels drastically reduced coupling. Although the hypothesis is straightforward that NO, either from intrinsic sources or generated by cells in close proximity to SON neurons, should enhance coupling, the effects of $\mathrm{NO}$ on coupling in other neuronal systems have not been entirely consistent. NO donors applied to striatal slices increased the incidence of coupling among medium spiny neurons (O'Donnell and Grace, 1997), for instance, whereas the same treatment applied to the retina has been found to uncouple the heterologous gap junctions between AII amacrine cells and bipolar cells (Mills and Massey, 1995). Horizontal cells also are uncoupled from each other by the administration of the NO precursor, L-arginine (Miyachi and Nishikawa, 1994). Here we present evidence that coupling among SON neurons is enhanced markedly by either exogenous (sodium nitroprusside, SNP) or endogenous (L-arginine) sources of NO generation. Further, these NO-mediated increases in coupling are blocked by the inhibition of various enzymes in the pathway, e.g., NOS and sGC. In addition, elevated intracellular cGMP was found to increase membrane conductance and depolarize both putative oxytocin and vasopressin cells, suggesting that endogenously generated NO increases both SON neuronal coupling and excitability.

\section{MATERIALS AND METHODS}

Animals and procedure. Experiments were performed on 167 slices prepared from as many young adult Sprague Dawley rats of both sexes (50-65 d old, except for the lactating rats, who were age 80-90 d). Of these, 46 rats were proestrus virgin females, 105 were males, and 16 were 
lactating, actively nursing mothers taken in approximately equal numbers on postpartum days 2, 4, 7, and 10. As in our previous studies (Yang and Hatton, 1987; Hatton and Yang, 1989, 1994) the animals were introduced gently and casually to a guillotine and decapitated, rapidly and nonstressfully, without anesthesia. Then, $400-\mu \mathrm{m}$-thick slices, prepared on a vibratome, were cut horizontally to avoid damage to the SON dendritic zone. Cut into oxygenated medium at room temperature, the slices then were transferred to either a static bath chamber (Hatton et al., 1980) or a perfusion chamber (Hatton et al., 1983) and maintained at $34-36^{\circ} \mathrm{C}$. Transillumination of the slice permitted visual guidance of the recording/ injecting electrode into the SON.

As is standard in our coupling experiments, only one neuron per SON was injected intracellularly with Lucifer yellow (LY). LY was the dye of choice for several reasons. First, we wished to compare the present results with those of our previous coupling studies; second, LY transfer requires relatively large junctional conductances (Dermietzel and Spray, 1993), permitting assessments of either increases or decreases in response to experimental treatments; and third, the determination of coupling incidence is rapid and direct, not requiring complex histochemical processing that also reduces the recovery rates of recorded and injected cells. After equivalent postinjection delays, the cells injected in control medium or medium containing other compounds were fixed in $4 \%$ buffered paraformaldehyde for $2 \mathrm{hr}$ and then transferred into Tris-buffered saline overnight. The slices were ethanol-dehydrated, cleared, and mounted on glass slides in methyl salicylate. LY-filled cells were located, counted, and photographed under epifluorescence, special attention being paid to dendrodendritic contacts, the sites of coupling between SON neurons (for review, see Hatton, 1997). Conventional intracellular recording procedures were used as in our previous coupling studies (Yang and Hatton, 1987, 1988; Hatton and Yang, 1994, 1996). Intracellular electrodes were filled with either 5\% LY (Stewart, 1978) in $0.25 \mathrm{~m}$ lithium acetate for coupling analyses or $1 \mathrm{M} \mathrm{K}$-acetate in studies of membrane conductance and excitability (resistances 80-180 M 2 ). Measurements of input conductance were made by passing brief hyperpolarizing current pulses $(100 \mathrm{pA}, 100 \mathrm{msec})$ through the recording electrode at rates from 0.6 to $1 \mathrm{~Hz}$. Recordings were made with the bridge circuit of a Neurodata Dual Intracellular Amplifier (New York, NY). Resting potentials were determined at the time of both entering and exiting the cell.

Solutions and drugs. The standard incubation medium was composed of (in mM): $126 \mathrm{NaCl}, 5.0 \mathrm{KCl}, 26 \mathrm{NaHCO}_{3}, 1.25 \mathrm{NaH}_{2} \mathrm{PO}_{4}, 1.3 \mathrm{MgSO}_{4}$, $2.4 \mathrm{CaCl}_{2}, 5$ organic buffer 3-( $N$-morpholino) propanesulfonic acid, and

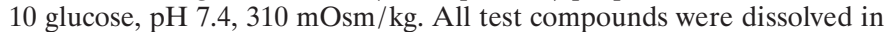
standard medium and delivered to the recording chamber. Drugs used were SNP (NO donor); hemoglobin or hydroxocobalamin (NO scavengers); L-arginine (NO precursor); the NOS inhibitor $N^{\omega}$-nitro-L-arginine methylester (L-NAME) and its inactive enantiomer, $N^{\omega}$-nitro-D-arginine methylester (D-NAME); cGMP; 8-bromo-cGMP; the GC inhibitors $1 \mathrm{H}$ $[1,2.4]$ oxadiazolo [4,3a] quinoxalin-1-one (ODQ), a selective blocker of NO-activated GC (Tocris Cookson, Ballwin, MO), or LY83583 (Calbiochem, La Jolla, CA). All other drugs were obtained from Sigma (St. Louis, MO).

Data analysis. Statistical analyses were performed by using Fisher's Exact Test on the numbers of single versus coupled cells observed for the different treatments. The ratios of the numbers of dye-coupled cells divided by the total number of dye-filled cells were calculated and used in this analysis. This measure is the well documented Dye Coupling Index and involves the same data analysis procedure used in our previous studies (Hatton and Yang, 1996). For purposes of graphic presentation the incidence of coupling is expressed as the number of coupled cells per injection. Thus, if each cell were coupled to one and only one other, this ratio would be 2.00 . When the incidence of coupling is low, the ratio approaches zero. In this study this index of coupling varied from a minimum of 0.20 to a maximum of 1.50 .

\section{RESULTS}

\section{Membrane characteristics and firing patterns}

The data that were analyzed were from 263 recorded SON neurons, 210 of which were LY-injected. The remaining 53 cells were studied for their responsiveness to the membraneimpermeant cGMP and to the membrane-permeant cGMP ana$\log$, 8-bromo-cGMP. These 263 neurons were from 46 virgin
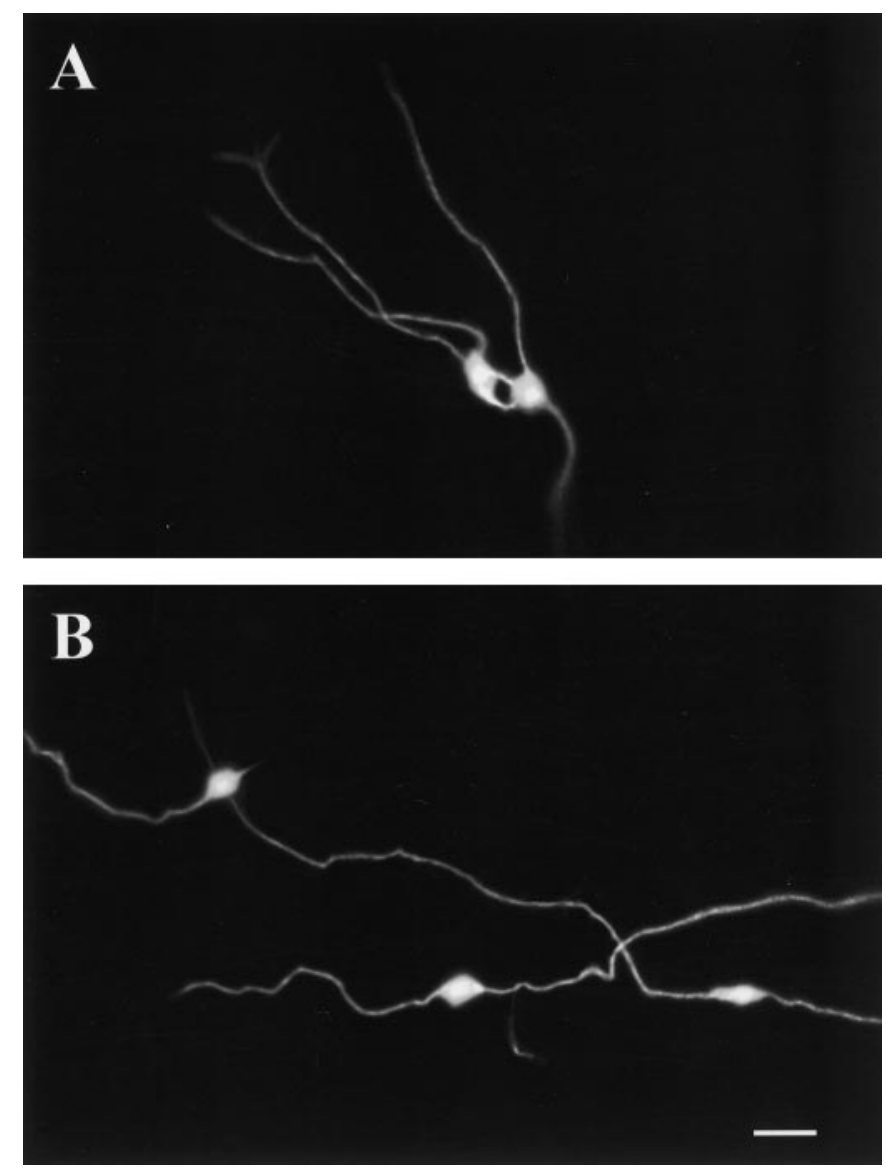

Figure 1. Fluorescence photomicrographs of LY-filled coupled neurons. In each case only one cell was injected. $A$, Coupled pair from SON of a virgin female brain slice treated with $500 \mu \mathrm{M}$ L-arginine. $B$, Coupled triplet from SON of a male brain slice treated with $100 \mu \mathrm{M}$ sodium nitroprusside. Note that all coupling is via the dendrites. Scale bar, $30 \mu \mathrm{m}$.

female, 105 male, and 16 lactating rats. The membrane characteristics, which were similar for all groups, were as follows (means \pm SEM for each measure): resting membrane potentials, $-57.5( \pm 1.3 \mathrm{mV})$; action potential amplitudes, $62.4( \pm 2.1 \mathrm{mV})$; input resistances, $132( \pm 6.4 \mathrm{M} \Omega$ ). Of the 210 recorded and injected neurons, 17 cells displayed slow-irregular firing rates of $<1 \mathrm{~Hz}, 26$ cells exhibited phasic bursting activity (typical of vasopressin neurons), and 113 cells displayed continuous firing, with rates ranging from 1 to $36 \mathrm{~Hz}$. Many of these were probably oxytocin cells (Poulain and Wakerley, 1982). The remaining 54 cells were not spontaneously active. Dye-coupling incidence was not associated selectively with any of these activity patterns. Typical examples of LY fills of SON neurons and of dye coupling observed in this study are shown in Figure 1. Note that all coupling involves the dendrites, as has been found consistently among SON cells.

\section{Effects of the NO precursor, L-arginine}

In our previous studies of coupling among SON neurons, we have found that virgin female rats consistently display low basal rates of coupling (Hatton et al., 1987; Yang and Hatton, 1987; Hatton and Yang, 1990). As seen in Figure 2, in slices taken from virgin females and incubated in standard control medium, there were 0.27 coupled neurons per injection. These data were based on 15 


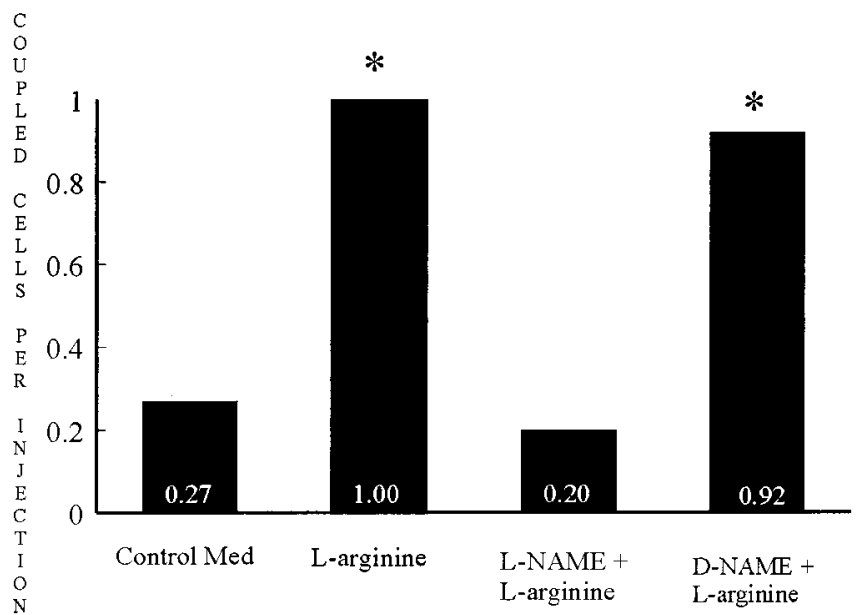

Figure 2. Effects of the NO precursor, L-arginine, and blockade of NO synthase on coupling. The number of coupled neurons per injection is given in four treatment groups of slices taken from proestrus virgin female rats. Shown are injections in slices incubated in standard medium (Control Med), $n=15$; in $500 \mu \mathrm{M} \mathrm{L}$-arginine, $n=10$; in $50 \mu \mathrm{M} \mathrm{L-NAME}$ $+500 \mu \mathrm{M} \mathrm{L}$-arginine, $n=10$; and in $50 \mu \mathrm{M} \mathrm{D}-\mathrm{NAME}+500 \mu \mathrm{M} \mathrm{L}$-arginine $(n=13)$. *Significantly different from Control Med at $p<0.03$.

injections that yielded 13 single and two coupled pairs of cells. Providing an abundance of the NOS substrate L-arginine (500 $\mu \mathrm{M})$ in the medium increased this index of coupling to 1.00 . This was based on 10 injections that yielded six single and 10 coupled cells, the latter consisting of two coupled pairs and two triplets. When similar slices were incubated with both $500 \mu \mathrm{M}$ L-arginine and a $50 \mu \mathrm{M}$ concentration of the NOS inhibitor, L-NAME, the precursor-induced coupling increase was abolished, because 10 injections yielded nine single and one coupled pair of cells. A similar result was obtained from 10 injections in slices bathed in $50 \mu \mathrm{M}$ L-NAME without L-arginine (data not shown). The inactive enantiomer, D-NAME, was ineffective in preventing the coupling increase: 13 injections produced eight single and 12 coupled cells, the latter consisting of three pairs and two triplets.

\section{Effect of the NO donor, SNP}

Figure 3 presents the data obtained when SNP $(100 \mu \mathrm{M})$ was added to the standard medium bathing slices from virgin female rats. Control data are presented for comparison. For the SNP treatment, 13 injections yielded seven single and 13 coupled cells, five pairs, and one triplet, or 1.00 coupled cells per injection. Incubating similar slices in medium containing $100 \mu \mathrm{M}$ SNP plus the NO scavenger hydroxocobalamin $(30 \mu \mathrm{M})$, after a $15 \mathrm{~min}$ preincubation in the medium containing the $30 \mu \mathrm{M}$ hydroxocobalamin alone, prevented this SNP-induced increase. Thus, 13 injections into cells in slices bathed in this medium yielded only four coupled cells, i.e., 11 single and two coupled pairs, similar to the control condition. To obviate the possible nonspecific effects of hydroxocobalamin, we repeated this experiment on slices from male rats, using hemoglobin as the NO scavenger (Fig. 4).

The incidence of LY coupling among SON neurons under basal conditions is significantly higher for males than for virgin females (Hatton and Yang, 1990). We sought to determine whether NO was capable of further increasing this already high coupling incidence in males. These data are shown in Figure 4. In standard control medium, 22 injections yielded 15 single and seven coupled pairs of cells ( 0.64 coupled cells per injection). In medium con-

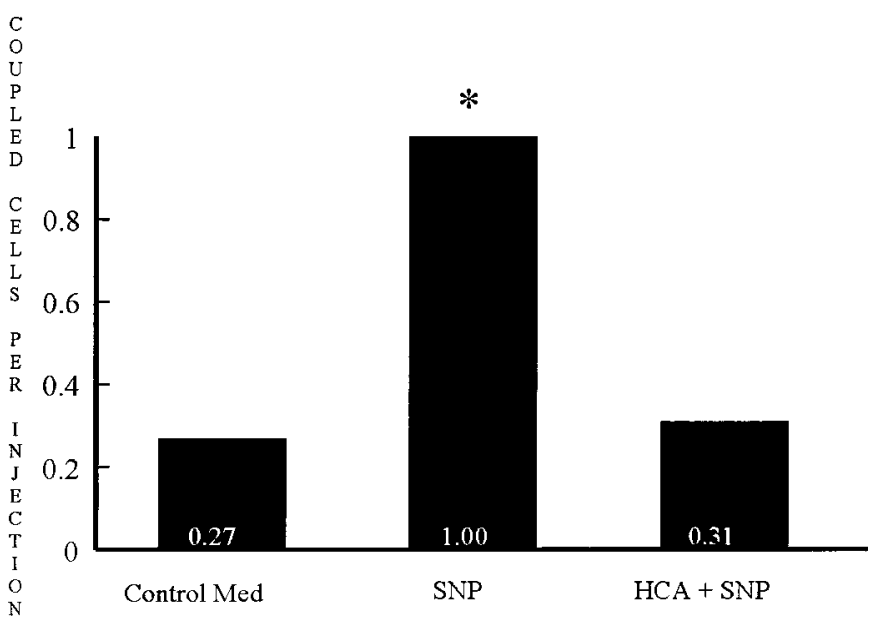

Figure 3. Effects of the NO donor, sodium nitroprusside (SNP), and SNP plus the NO scavenger hydroxocobalamin $(H C A)$ on coupling. The number of coupled neurons per injection is given in three treatment groups of slices taken from proestrus virgin female rats. The Control Med group is the same as in Figure 2. Shown are injections in slices incubated in standard medium containing $100 \mu \mathrm{M} \mathrm{SNP}(n=13)$ and in $30 \mu \mathrm{M} \mathrm{HCA} \mathrm{+}$ $100 \mu \mathrm{M}$ SNP $(n=13)$. *Significantly different from both groups at $p<$ 0.02 .

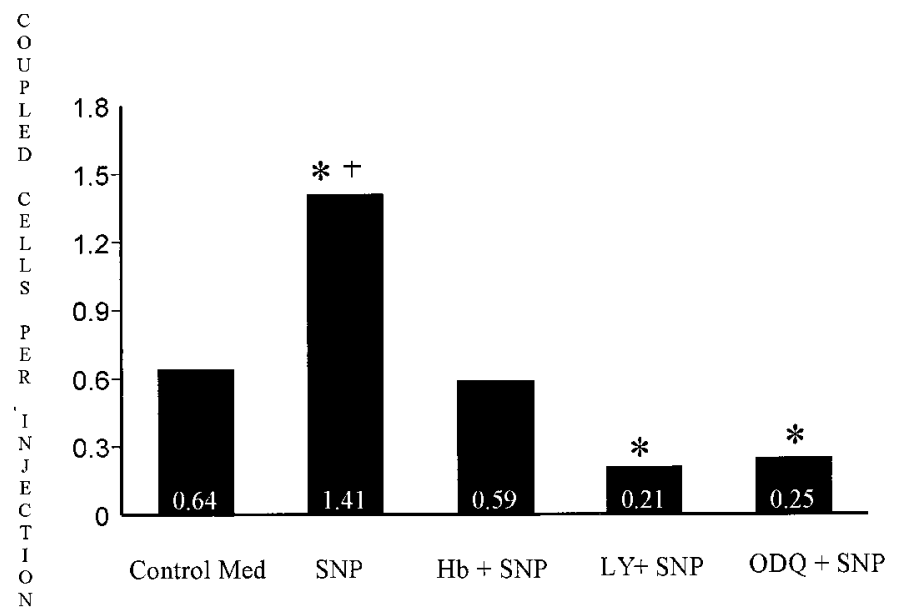

Figure 4. Effects on coupling of SNP administered along with either hemoglobin $(H b)$ or the guanylyl cyclase inhibitors LY83583 $(L Y)$ or ODQ. The number of coupled neurons per injection is given in five treatment groups of slices taken from male rats. Shown are injections in slices maintained in Control Med $(n=22)$, in $100 \mu \mathrm{M} \mathrm{SNP}(n=17)$, in 20 $\mu \mathrm{m} \mathrm{Hb}+S N P(n=17)$, in $10 \mu \mathrm{M} L Y+S N P(n=8)$, or in $10 \mu \mathrm{m}$ $O D Q+S N P(n=9)$. ${ }^{*}$ Significantly different from Control Med and $H B+S N P$ at $p<0.05$. 'Significantly different from $H b+S N P, L Y+S N P$, and $O D Q+S N P$ at $p<0.01$.

taining $100 \mu \mathrm{M}$ SNP, 17 injections yielded five pairs, two triplets, and two quadruplets, or 24 coupled cells (1.41 coupled cells per injection). As in the females, SNP-induced coupling was prevented in males by a NO scavenger. Seventeen injections produced 12 single cells and five coupled pairs in slices bathed in medium containing $20 \mu \mathrm{m}$ of hemoglobin plus $100 \mu \mathrm{m}$ of SNP. To confirm the hypothesis that NO has its action on coupling in these cells via the activation of GC, we incubated similar slices from males in medium containing $100 \mu \mathrm{M}$ SNP plus the GC inhibitor LY83583 $(10 \mu \mathrm{M})$. Nineteen LY injections yielded 17 single and two coupled pairs of cells ( 0.21 coupled cells per 


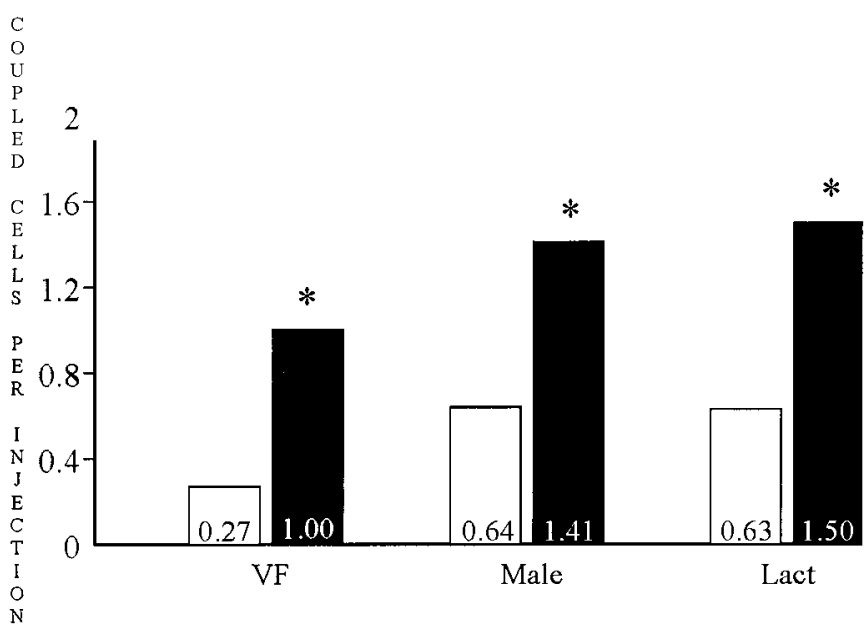

Figure 5. Comparison of basal levels of coupling in control medium (open bars) and in medium containing $100 \mu \mathrm{M}$ SNP (filled bars) on coupling in slices taken from virgin female, male, and lactating rats. For lactating rats the injections are shown in control medium $(n=19)$ and in SNP-containing medium $(n=12)$; the other groups are the same as in Figures 3 and 4 . *Significantly different from own control at $p<0.02$ 0.03 . The relatively small number of injections in control medium in this study resulted in nonsignificant differences between the control groups.

injection). Similar results were obtained by using ODQ $(10 \mu \mathrm{m})$, a selective blocker of the NO-activated sGC. Twenty injections yielded 18 single fills, one pair and one triplet ( 0.25 coupled cells per injection). As seen in Figure 4, these treatments reduced the coupling to significantly below the male control levels. This suggests that there is baseline NO release that activates a basal level of sGC and that this activity has a tonic role in basal levels of interneuronal coupling in male SONs.

Lactating rats also display incidences of coupling that are elevated over virgin females (Hatton et al., 1987; Yang and Hatton, 1987; Hatton and Yang, 1990, 1994). Coupling among SON cells from lactating rats also was enhanced by SNP (Fig. 5, right). In control medium, 19 injections produced 13 single and six coupled pairs ( 0.63 coupled cells per injection), whereas in SNP-containing medium $(100 \mu \mathrm{M}) 12$ injections resulted in four single and 18 coupled cells, consisting of three pairs and four triplets (1.50 coupled cells per injection). There were no discernible differences in coupling attributable to the number of days in lactation in either the control or SNP groups.

Summarized in Figure 5 are the comparisons of control and SNP conditions for the three types of animals in this study. Clearly the largest increase induced by the NO donor is in the virgin females, who had the lowest basal incidence of coupling.

\section{Effects of 8-bromo-cGMP on neuronal excitability}

Responses to cGMP and 8-bromo-cGMP were studied in a separate set of 38 phasically firing and 15 continuously firing neurons, all from male rats. Twenty-one of the phasically firing cells were recorded before and during a change in the bath concentration of 8-bromo-cGMP from 0 to $2 \mathrm{~mm}$. For the other 14 cells, responses to nanodrop applications of the cGMP analog (1 mM) on the slice surface were studied. Of the 35 neurons tested, two showed no response (one each for the bath-applied and nanodrop applications). The remaining 33 cells showed membrane depolarizations in response to the 8-bromo-cGMP. Fifteen neurons studied at normal resting potential of approximately $-58 \mathrm{mV}$ were depolarized by $6-10 \mathrm{mV}$, with some apparent dependence on the duration and/or concentration of the nucleotide application (Fig. $6 A-C)$. In each case the durations of the phasic bursts were increased also. Figure $6 \mathrm{C}$ shows that the membrane-impermeant cGMP had no effect on either the membrane potential or the phasic bursts.

Membrane conductance changes were measured in 26 neurons. Conductance increases in response to bath applications of 8-bromo-cGMP, but not to cGMP, were observed in all 20 of these cells. These increases in conductance are seen in Figure 7, $A$ and $C$, in which a steady negative current moved the pre-8bromo-cGMP membrane potential to below spike threshold. In response to 8-bromo-cGMP the cells depolarized and fired bursts of action potentials. Previous incubation with the GC blocker LY83583 also had no effect on the ability of 8-bromo-cGMP to depolarize and evoke phasic bursting. The twelve continuously firing SON neurons were depolarized, increased their firing rates, and showed increased membrane conductances in response to these same concentrations of 8-bromo-cGMP (Fig. 8). To determine whether the increased conductance seen in response to 8-bromo-cGMP was attributable simply to membrane depolarization, we current-clamped slices pretreated with LY83583 just below resting potential and bath-applied the 8-bromo-cGMP. Figure 9 shows that the conductance change occurred without membrane depolarization in six of six cells tested.

\section{DISCUSSION}

Evidence presented here indicates that either exogenously supplied or endogenously generated NO increases dye coupling among neurons in the SON. Furthermore, increases are mediated by cGMP-dependent mechanisms, possibly involving protein kinase $\mathrm{G}$ and the phosphorylation of gap junction-associated proteins. Elucidation of these latter steps in the process awaits further research. NO has been shown to have similar enhancing effects on coupling among medium spiny neurons in the striatum (O'Donnell and Grace, 1997) but has been shown to be an uncoupler of neurons in the retina (Miyachi and Nishikawa, 1994; Mills and Massey, 1995). Such cell-, connexin-, and messengerspecific regulation of junctional permeability now is becoming recognized as the rule rather than the exception (Bennett et al., 1991; Bennett, 1997; Hatton, 1999). In the present study both the numbers of coupled pairs of neurons and the numbers of neurons coupled to two or three others were increased by NO, indicating that the coupled network was expanded by this messenger. Similar effects on the incidence and extent of coupling were obtained in earlier studies in which coupling increases were induced by physiologically activating conditions or by stimulation of excitatory afferents to the SON (Hatton et al., 1987; Yang and Hatton, 1987; Hatton and Yang, 1990, 1996). Although cell type (i.e., oxytocin or vasopressin) was not determined immunocytochemically in the present study, the observed coupling increases were represented in cells across all of the identified firing patterns and, thus, NO most likely had similar effects on coupling among both oxytocin and vasopressin neurons. The actual incidence and extent of coupling revealed by LY dye transfer in this study is an underestimate of the actual coupling that exists among these neurons, because these numbers are seen to be many-fold larger when a less highly charged and smaller tracer molecule (e.g., neurobiotin) is used to estimate coupling incidence (Hatton and Yang, 1994). Similar, but even more dramatic, differences between LY and neurobiotin coupling have been reported in the neocortex and retina (Vaney, 1991; Peinado et al., 1994). 


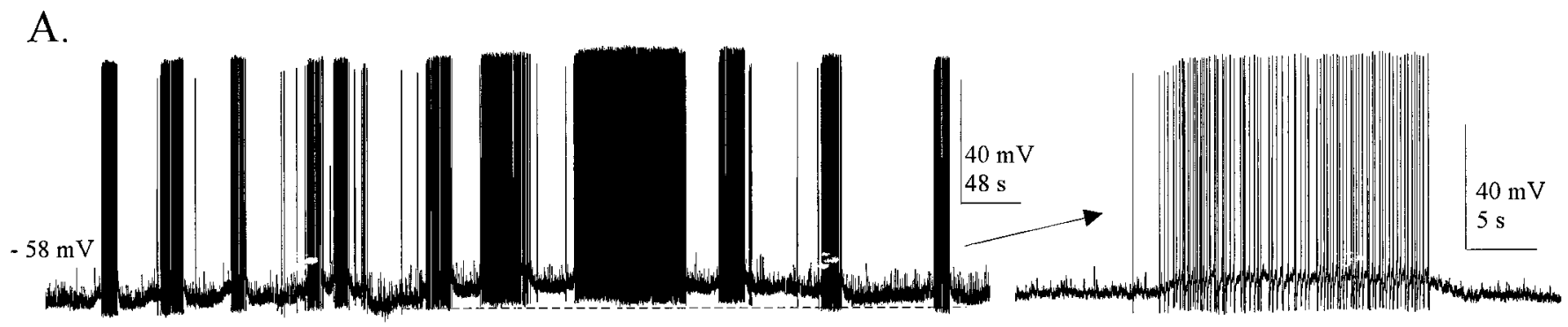

8-Br-cGMP $1 \mathrm{mM}$

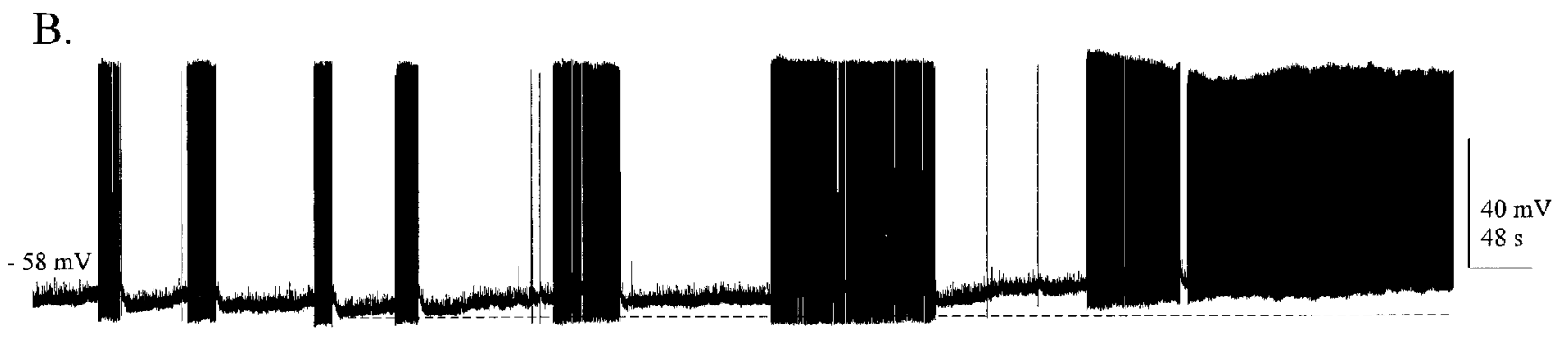

8-Br-cGMP $2 \mathrm{mM}$

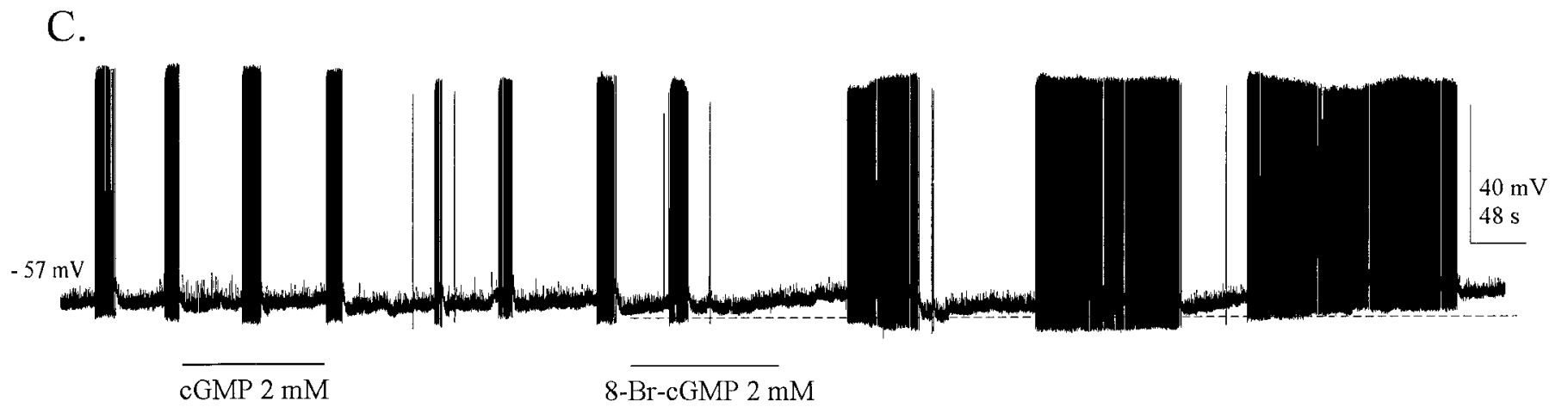

Figure 6. Effects of 8-bromo-cGMP on membrane potential and burst duration of phasically firing, putative vasopressin neurons. $A$, The addition of 8-bromo-cGMP to the medium resulted in depolarization from normal membrane potential (dashed line) and increased burst duration. The end burst is expanded to show burst structure and apparent plateau potential. $B$, These effects were repeatable 10 min later after a return to baseline activity. $C$, Increasing the concentration of 8-bromo-cGMP from 1 to $2 \mathrm{~mm}$ induced apparently larger effects on membrane potential and burst duration (compare $A$ and $C$ ). Note in $C$ that 2 mM cGMP had no effect. $A$ and $B$ are the same cell; $C$ is a different cell.

\section{Relation to hormone demand}

Increased coupling among SON neurons is associated consistently with physiological conditions of increased demand for peptide synthesis and release, e.g., dehydration (Cobbett and Hatton, 1984) or lactation (Hatton et al., 1987; Yang and Hatton, 1987). Similarly, the physiological activation of this system during dehydration or lactation has been found to result in an upregulation of NOS (Villar et al., 1994; Blazquez et al., 1995; Wang and Morris, 1996) and/or its mRNA (Ceccatelli and Eriksson, 1993; Kadowaki et al., 1994; Ueta et al., 1995; Ceccatelli, 1997). SNP, IL-2, and acetylcholine also have been shown to release vasopressin from hypothalamic slices. The effects of the latter two substances were blocked by inhibition of NOS, indicating that their actions were via this pathway (Raber and Bloom, 1994). Unfortunately, no attempt was made in that study to determine whether the peptide release was dependent on NO activation of sGC, although this is probable. Finally, L-arginine or NO donors administered intracerebroventricularly are capable of evoking vasopressin release in vivo (Ota et al., 1993). Curiously, however, intracerebroventricular administration of NOS inhibitors has been found to facilitate the dehydration-induced release of oxytocin (SummyLong et al., 1993). It is difficult to discern the locus of action of drugs placed into the ventricle, and effects at the level of the hypothalamic neurons may differ from those at the neurohypophysis. Nonetheless, it appears that there is a close positive relationship among physiological activation of this system, peptide release, upregulation of NOS, and increased coupling among the neurons of at least the SON portion of the system.

\section{Synaptic modulation of coupling}

Two studies have shown that the brief activation of two different monosynaptic afferent pathways to SON neurons was effective in 

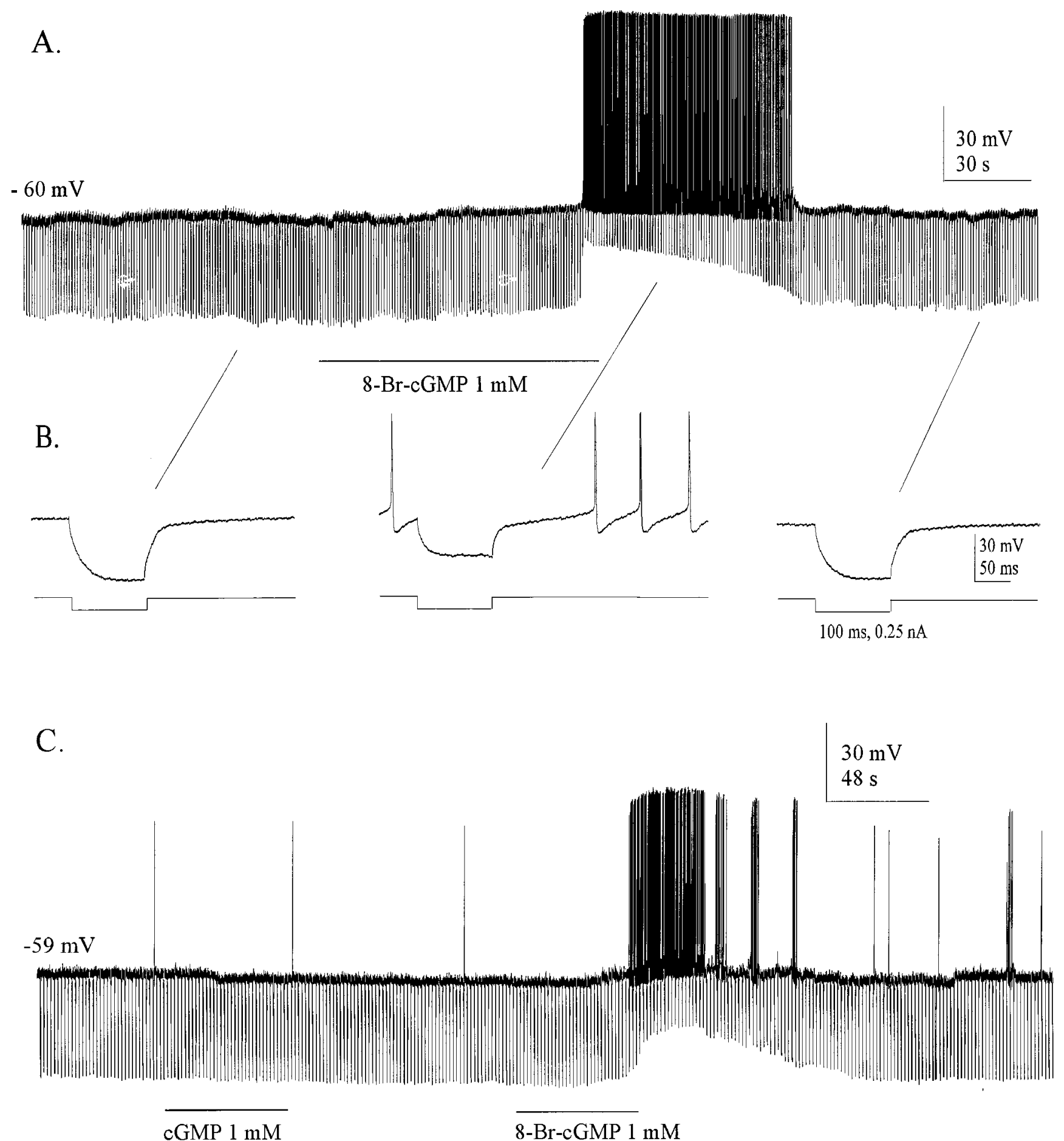

Figure 7. Effects of $1 \mathrm{~mm}$ 8-bromo-cGMP on membrane conductances of two different phasically firing cells $(A, C)$ current-clamped at or slightly below spike threshold by steady hyperpolarizing current $(-0.05 \mathrm{nA})$. Pulses of hyperpolarizing current (detailed in $B$ ) were administered at $1 \mathrm{~Hz}$ to monitor conductance changes. In each case the bath application of 8-bromo-cGMP produced an increase in conductance that was accompanied by a burst of action potentials. No effect on conductance was seen in response to the application of cGMP $(C)$. Both cells were pretreated with LY83583 to block endogenous GC activity.

modulating coupling. The first of these studies (Hatton and Yang, 1990) involved the stimulation of the lateral olfactory tract for 10 min at $10 \mathrm{~Hz}$, which resulted in a significant increase in coupling among the neurons of the SONs from lactating rats, but not from males or virgin females. This experimental outcome was puzzling because, at that time, little was known about NO either as an interneuronal or intraneuronal messenger, the long-lasting intracellular consequences of ionotropic glutamate receptor activation, or the plasticity of glutamate receptor expression. Subsequent work, including the present study, indicates that all of these factors appear to have played roles in the effects leading to those earlier results. Thus, lateral olfactory tract stimulation activates 
A.

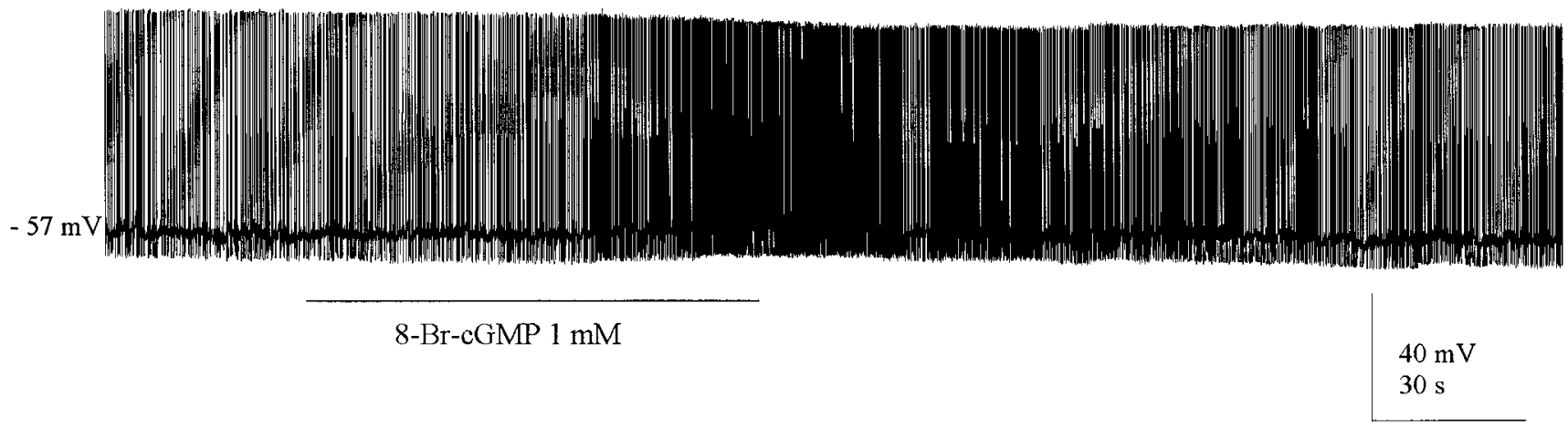

B.

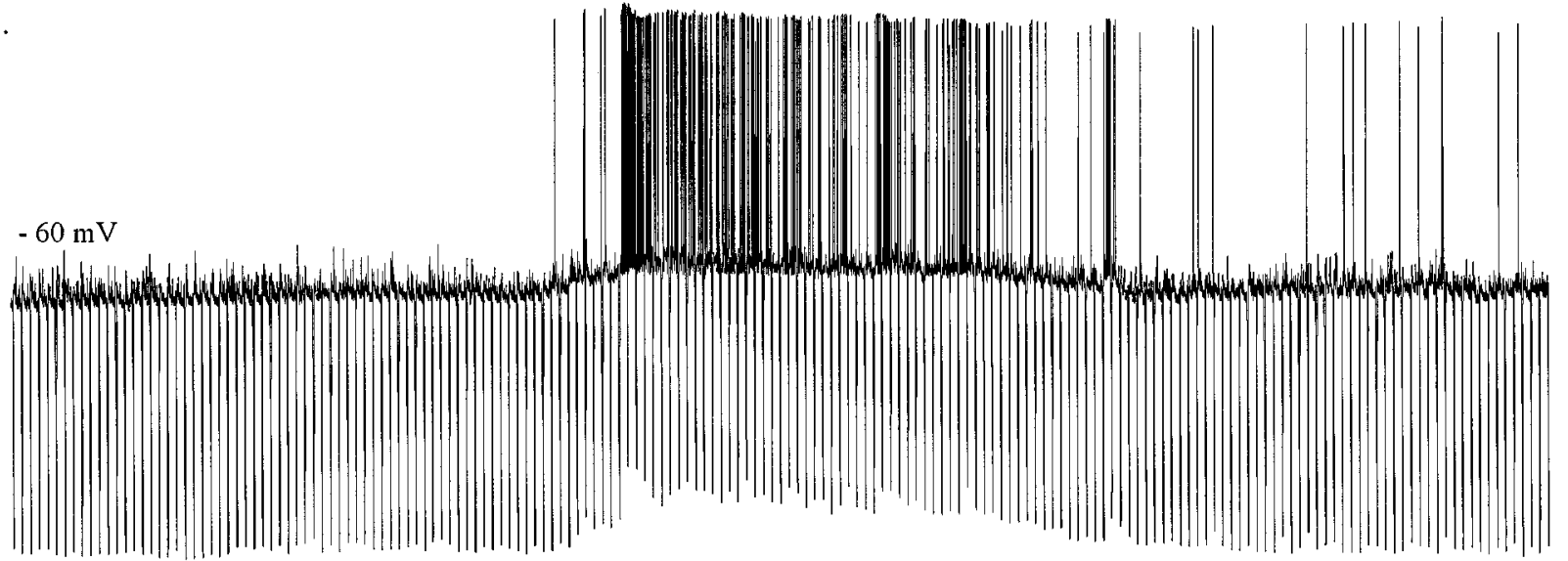

C.
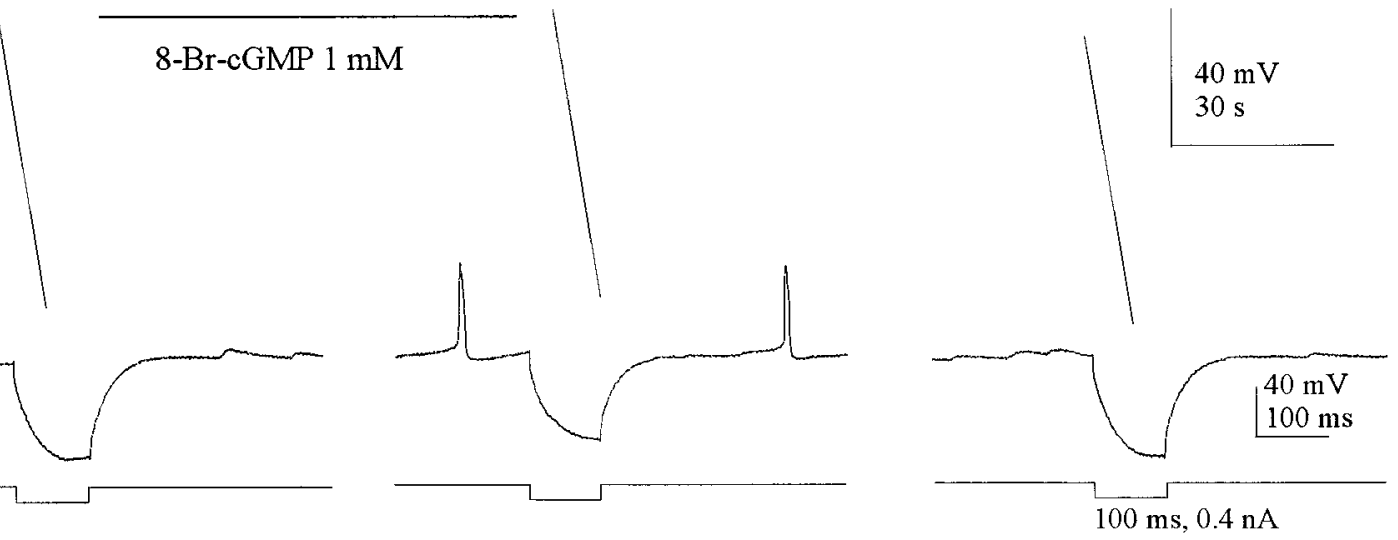

Figure 8. Effects of 8-bromo-cGMP on membrane potential and firing frequency $(A)$ and on conductance $(B, C)$ of two continuously firing neurons. Both cells were pretreated with LY83583 to block endogenous GC activity.

both NMDA and non-NMDA receptors (Yang et al., 1995), primarily on SON dendrites (Smithson et al., 1989, 1992) where the coupling occurs (see Fig. 2). NMDA receptors (Meeker et al., 1994), as well as NOS (noted above), are upregulated by the physiological stimulation of the magnocellular system. This may account for the differential response of lactating versus virgin female or males rats to the extent that lactation, like dehydration, is a general activating stimulus in this system (see Hatton, 1997).
NMDA receptor-mediated increases in intracellular $\mathrm{Ca}^{2+}$ result in $\mathrm{Ca}^{2+}$ /calmodulin activation of NOS, with the subsequent production of NO, activation of sGC, and the accumulation of cGMP.

Investigation of a second monosynaptic pathway identified the cGMP-dependent mechanisms as important enhancers of SON neuronal coupling (Hatton and Yang, 1996). Stimulation of the tuberomamillary nucleus resulted in prolonged enhancement of excitability in SON vasopressin neurons via $\mathrm{H}_{1}$-histamine recep- 


\section{A.}

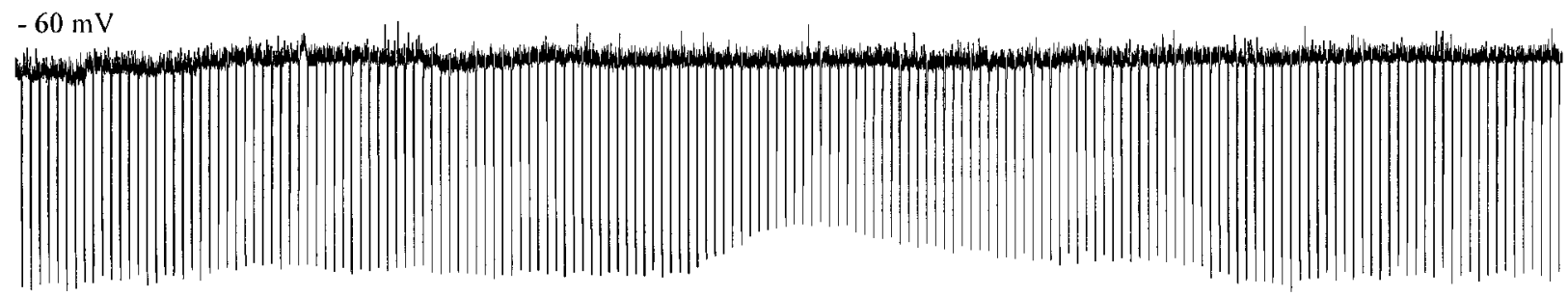

8-Br-cGMP $1 \mathrm{mM}$

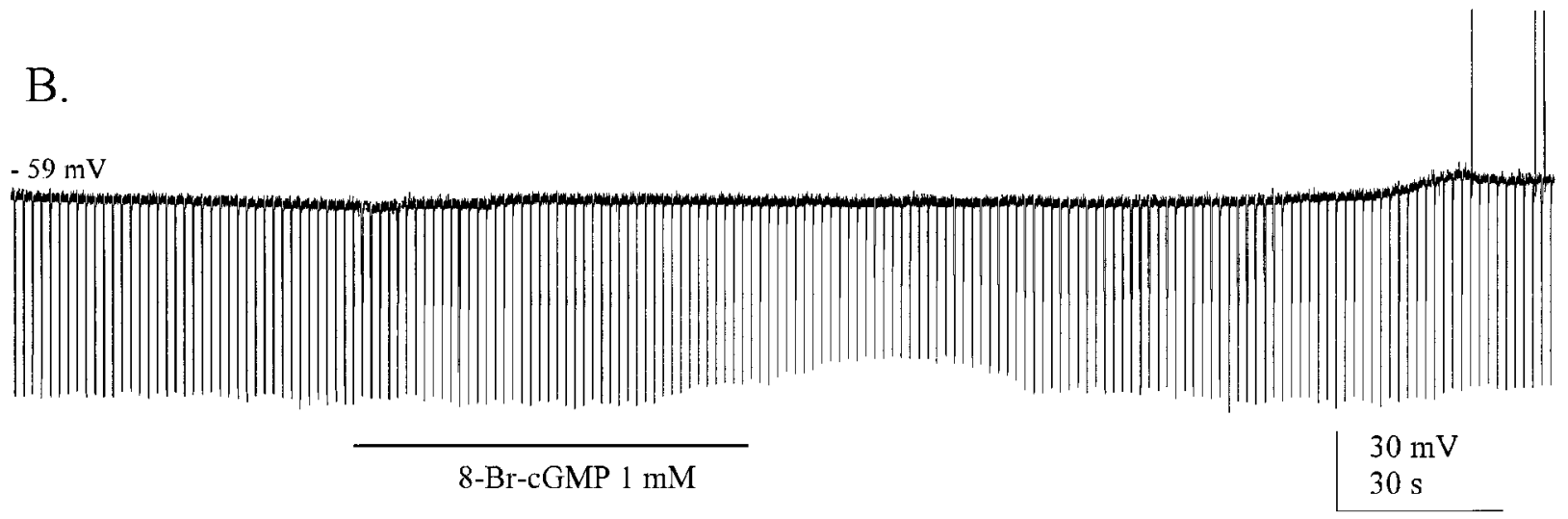

Figure 9. Effects of bath-applied 8-bromo-cGMP on membrane conductance of two cells, one phasically $(A)$ and one continuously $(B)$ firing, for which the membrane potentials were current-clamped at $1-2 \mathrm{mV}$ below resting potential. Both slices in which these cells were recorded were pretreated with LY83583 to block endogenous guanylyl cyclase activity.

tors that are linked via G-proteins to the activation of GC. Receptor activation by both the stimulation and incubation of the slices in 8-bromo-cGMP resulted in dramatic increases in coupling. Conversely, 8-bromo-cAMP sharply reduced coupling. One pathway involved in this G-protein-mediated response to histamine involves a cascade of phospholipase C-diacyl glycerolprotein kinase $\mathrm{C}$ activation of NOS. Therefore, it is likely that these two excitatory inputs (i.e., glutamatergic and histaminergic) converge via the NOS-NO steps investigated in the present study to use the same cGMP-dependent mechanisms in the modulation of coupling.

\section{Sex differences}

One clue to the consistently observed sex differences in the basal incidence of coupling emerged from the present findings. Inhibition of either GC by LY83583 or sGC by ODQ reduced coupling in slices from males to the same level as that found in the control virgin females ( $\sim 0.25$ coupled cell per injection). This suggests that the sex difference may be attributable to differential GC or adenylyl cyclase activity levels in males and virgin females. Sex steroids may play an influencing role in regulating the levels of these enzymes, because the presence of testosterone has been found to be necessary to maintain the high coupling incidence typical of males (Cobbett et al., 1987). Similarly, the presence of estrogen maintains the relatively low incidence of coupling observed in virgin females (Hatton et al., 1992), and the more frequent coupling always found in lactating rats is accompanied by plasma estrogen at its nadir (Taya and Greenwald, 1982).

\section{Possible functional roles}

NO release from magnocellular neurons may have a great many functional consequences. Increased coupling among oxytocin neurons in lactation is hypothesized to play a role in the synchronization of bursting among these cells that occurs just before each milk ejection during suckling of the pups (Hatton, 1997). The weak coupling (Yang and Hatton, 1988) among vasopressin neurons should not produce synchrony, but it appears to contribute importantly to their phasic bursting patterns of firing, which are eliminated by uncoupling agents (Li et al., 1998), patterns without which vasopressin release is inefficient or lacking (Dutton and Dyball, 1979). NO may influence vasopressin release via its effect on expanding the network of metabolically coupled neurons that fire phasically, although asynchronously.

It is clear from the results presented here that the NO-induced activation of $\mathrm{sGC}$ and the consequent accumulation of cGMP 
that normally ensues not only affect coupling but are also capable of inducing or enhancing SON neuronal excitability. The membrane depolarization and conductance increases observed in response to elevated intracellular cGMP in both putative oxytocin and vasopressin cells suggest that the resultant action of endogenously released NO would be to increase hormone release. Such release may be selective for one or the other of the two peptides, depending on the spatial extent of NO penetration within the SON, because its effective sphere of influence is only $\sim 200 \mu \mathrm{m}$ (Wood and Garthwaite, 1994). It should be noted that, although we observed substantial cGMP-dependent membrane depolarizations and prolongation of phasic bursts, two earlier studies of a few SON cells each found either no effect or slight hyperpolarizations in response to $0.5 \mathrm{~mm}$ 8-bromo-cGMP (Akamatsu et al., 1993; Cui et al., 1994). No obvious explanation for this apparent discrepancy presents itself.

Another functional consequence of NO released from magnocellular neurons may be the dilation of local blood vessels, including those that are found in extremely high density and close proximity to the neurons in the SON. This would have the beneficial effect of increasing blood flow, the delivery of nutrients, and the removal of metabolites (for review, see Iadecola, 1993).

\section{REFERENCES}

Akamatsu N, Inenaga K, Yamashita H (1993) Inhibitory effects of natriuretic peptides on vasopressin neuron mediated through cGMP and cGMP-dependent protein kinase in vitro. J Neuroendocrinol 5:517-522.

Bennett MVL (1997) Gap junctions as electrical synapses. J Neurocytol 26:349-366.

Bennett MVL, Barrio LC, Bargiello TA, Spray DC, Hertzberg E, Saez JC (1991) Gap junctions: new tools, new answers, new questions. Neuron 6:305-320.

Blazquez JL, Pelaez B, Pastor FE, Lopez RM, Amat P (1995) NADPHdiaphorase activity in the rat hypothalamo-neurohypophysial system after salt loading and rehydration. Biomed Res 16:405-410.

Bredt DS, Hwang PM, Snyder SH (1990) Localization of nitric oxide synthase indicating a neural role for nitric oxide. Nature 347:768-770.

Ceccatelli S (1997) Expression and plasticity of NO synthase in the neuroendocrine system. Brain Res Bull 44:533-538.

Ceccatelli S, Eriksson M (1993) The effect of lactation on nitric oxide synthase gene expression. Brain Res 625:177-179.

Cobbett P, Hatton GI (1984) Dye coupling in hypothalamic slices: dependence on in vivo hydration state and osmolality of incubation medium. J Neurosci 4:3034-3038.

Cobbett P, Yang QZ, Hatton GI (1987) Incidence of dye coupling among magnocellular paraventricular neurons in male rats is testosterone-dependent. Brain Res Bull 18:365-370.

Cui L-N, Inenaga K, Nagatomo T, Yamashita H (1994) Sodium nitroprusside modulates NMDA response in rat supraoptic neurons in vitro. Brain Res Bull 35:253-260.

Dawson TM, Bredt DS, Fotuhi M, Hwang PM, Snyder SH (1991) Nitric oxide synthase and neuronal NADPH diaphorase are identical in brain and peripheral tissues. Proc Natl Acad Sci USA 88:7797-7801.

Dermietzel R, Spray DC (1993) Gap junctions in the brain: where, what type, how many, and why? Trends Neurosci 16:186-192.

Dutton A, Dyball REJ (1979) Phasic firing enhances vasopressin release from the rat neurohypophysis. J Physiol (Lond) 290:433-440.

Furuyama T, Inagaki S, Takagi H (1993) Localizations of $\alpha 1$ and $\beta 1$ subunits of soluble guanylate cyclase in the rat brain. Mol Brain Res 20:335-344.

Hatton GI (1997) Function-related plasticity in hypothalamus. Annu Rev Neurosci 20:375-397.

Hatton GI (1999) Synaptic modulation of neuronal coupling. Cell Biol Int, in press.

Hatton GI, Yang QZ (1989) Supraoptic nucleus afferents from the main olfactory bulb. II. Intracellularly recorded responses to lateral olfactory tract stimulation in rat brain slices. Neuroscience 31:289-297.
Hatton GI, Yang QZ (1990) Activation of excitatory amino acid inputs to supraoptic neurons. I. Induced increases in dye-coupling in lactating, but not virgin or male, rats. Brain Res 513:264-269.

Hatton GI, Yang QZ (1994) Incidence of neuronal coupling in supraoptic nuclei of virgin and lactating rats: estimation by neurobiotin and Lucifer yellow. Brain Res 650:63-69.

Hatton GI, Yang QZ (1996) Synaptically released histamine increases dye coupling among vasopressinergic neurons of the supraoptic nucleus: mediation by $\mathrm{H}_{1}$ receptors and cyclic nucleotides. J Neurosci 16:123-129.

Hatton GI, Doran AD, Salm AK, Tweedle CD (1980) Brain slice preparation: hypothalamus. Brain Res Bull 5:405-414.

Hatton GI, Ho YW, Mason WT (1983) Synaptic activation of phasic bursting in rat supraoptic nucleus neurones recorded in hypothalamic slices. J Physiol (Lond) 345:297-317.

Hatton GI, Yang QZ, Cobbett P (1987) Dye coupling among immunocytochemically identified neurons in the supraoptic nucleus: increased incidence in lactating rat. Neuroscience 21:923-930.

Hatton GI, Yang QZ, Koran LE (1992) Effects of ovariectomy and estrogen replacement on dye coupling among rat supraoptic nucleus neurons. Brain Res 572:291-295.

Iadecola C (1993) Regulation of the cerebral microcirculation during neural activity: is nitric oxide the missing link? Trends Neurosci 16:206-214.

Kadowaki K, Kishimoto J, Leng G, Emson PC (1994) Up-regulation of nitric oxide synthase (NOS) gene expression together with NOS activity in the rat hypothalamo-hypophysial system after chronic salt loading: evidence of a neuromodulatory role of nitric oxide in arginine vasopressin and oxytocin secretion. Endocrinology 134:1011-1017.

Li Z-H, Kumamoto K, Mercier F, Hatton GI (1998) Gap junctional communication is closely associated with expression of slow depolarizations in supraoptic nucleus neurons. Soc Neurosci Abstr 24:1850.

Meeker RB, McGinnis S, Greenwood RS, Hayward JN (1994) Increased hypothalamic glutamate receptors induced by water deprivation. Neuroendocrinology 60:477-485.

Mills SL, Massey SC (1995) Differential properties of two gap junctional pathways made by AII amacrine cells. Nature 377:734-737.

Miyachi EI, Nishikawa C (1994) Blocking effect of L-arginine on retinal gap junctions by activating guanylate cyclase via generation of nitric oxide. Biogenic Amines 10:459-464.

O'Donnell P, Grace AA (1997) Cortical afferents modulate striatal gap junction permeability via nitric oxide. Neuroscience 76:1-5.

Ota M, Crofton JT, Festavan GT, Share L (1993) Evidence that nitric oxide can act centrally to stimulate vasopressin release. Neuroendocrinology 57:955-959.

Peinado A, Yuste R, Katz LC (1994) Extensive dye coupling between rat neocortical neurons during the period of circuit formation. Neuron 10:103-114.

Poulain DA, Wakerley JB (1982) Electrophysiology of hypothalamic magnocellular neurones secreting oxytocin and vasopressin. Neuroscience 7:773-808.

Raber J, Bloom FE (1994) IL-2 induces vasopressin release from the hypothalamus and the amygdala: role of nitric oxide-mediated signaling. J Neurosci 14:6187-6195.

Sanchez F, Alonso JR, Arevalo R, Blanco E, Aijon J, Vazquez R (1994) Coexistence of NADPH-diaphorase with vasopressin and oxytocin in the hypothalamic magnocellular neurosecretory nuclei of the rat. Cell Tissue Res 276:31-34.

Smithson KG, Weiss ML, Hatton GI (1989) Supraoptic nucleus afferents from the main olfactory bulb. I. Anatomical evidence from anterograde and retrograde tracers in rat. Neuroscience 31:277-287.

Smithson KG, Weiss ML, Hatton GI (1992) Supraoptic nucleus afferents from the accessory olfactory bulb: evidence from anterograde and retrograde tract tracing in the rat. Brain Res Bull 29:209-220.

Southam E, Garthwaite J (1993) The nitric oxide-cyclic GMP signaling pathway in rat brain. Neuropharmacology 32:1267-1277.

Stewart WW (1978) Functional connections between cells as revealed by dye-coupling with a highly fluorescent naphthalimide tracer. Cell 14:741-759.

Summy-Long JY, Bui V, Mantz S, Koehler E, Weisz J, Kadekaro M (1993) Central inhibition of nitric oxide synthase preferentially augments release of oxytocin during dehydration. Neurosci Lett 152:190-193. 
Taya K, Greenwald GS (1982) Mechanisms of suppression of ovarian follicular development during lactation in the rat. Biol Reprod 27:1090-1101.

Ueta Y, Yamashita H, Kawata M, Koizumi K (1995) Water deprivation induces regional expression of c-fos protein in the brain of inbred polydipsic mice. Brain Res 677:221-228.

Vaney DI (1991) Many diverse types of retinal neurons show tracer coupling when injected with biocytin or neurobiotin. Neurosci Lett125: 187-190.

Villar MJ, Ceccatelli S, Ronnqvist M, Hokfelt T (1994) Nitric oxide synthase increases in hypothalamic magnocellular neurons after salt loading in the rat. An immunohistochemical and in situ hybridization study. Brain Res 644:273-281.

Wang H, Morris JF (1996) Constitutive nitric oxide synthase in hypo- thalami of normal and hereditary diabetes insipidus rats and mice: role of nitric oxide in osmotic regulation and its mechanism. Endocrinology 137:1745-1751.

Wood J, Garthwaite J (1994) Models of the diff usional spread of nitric oxide: implications for neural nitric oxide signaling and its pharmacological properties. Neuropharmacology 33:1235-1244.

Yang QZ, Hatton GI (1987) Dye coupling among supraoptic nucleus neurons without dendritic damage: differential incidence in nursing mother and virgin rats. Brain Res Bull 19:559-565.

Yang QZ, Hatton GI (1988) Direct evidence for electrical coupling among rat supraoptic nucleus neurons. Brain Res 463:47-56.

Yang QZ, Smithson KG, Hatton GI (1995) NMDA and non-NMDA receptors on rat supraoptic nucleus neurons activated monosynaptically by olfactory afferents. Brain Res 680:207-216. 